\title{
Desenvolvimento de plantas e produção de sementes de Amaranthus tricolor L. ${ }^{1}$
}

\author{
GISLAINE RICARDO DA ROCHA ${ }^{2} \mathrm{e}$

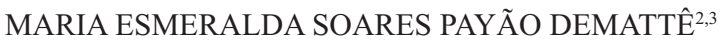

\begin{abstract}
RESUMO
O desenvolvimento e a produção de sementes de Amaranthus tricolor $\mathrm{L}$. foram avaliados em Jaboticabal (SP), de 1999 a 2000. As mudas foram produzidas em tubetes e, depois, transplantadas para canteiro a pleno sol, em espaçamento de $25 \times 25 \mathrm{~cm}$. Houve alta porcentagem de mortalidade após o transplante, e as plantas sobreviventes não se desenvolveram bem. A porcentagem e a velocidade de germinação das sementes produzidas foram mais baixas do que as das sementes inicialmente utilizadas. Ficou confirmada, entretanto, a possibilidade de produzir sementes da espécie em Jaboticabal, recomendando-se, para continuação da pesquisa, que a semeadura seja feita em canteiro definitivo.
\end{abstract}

Palavras-chave: Amaranthus tricolor L, crescimento, produção de sementes, plantas ornamentais.

\section{ABSTRACT \\ Plant growth and seed production of Amaranthus tricolor L.}

Plant development and seed production of red amaranth (Amaranthus tricolor L.) were evaluated at Jaboticabal State of São Paulo, Brazil, through 1999-2000. Seedlings were produced in small plastic containers, and transplanted to a bed exposed to full sun in a $25 \times 25 \mathrm{~cm}$ spacing. High percentage of mortality occurred after transplanting, and the surviving plants did not grow well. Germination percentage and speed of the yielded seeds were lower than that of the seeds initially used to grow the studied plants. However, the possibility to produce seeds of this species at Jaboticabal was confirmed. Direct sowing in beds is recommended for future experiments.

Keywords: Amaranthus tricolor L, plant growth, seed production, ornamental plants.

\section{INTRODUÇÃO}

Amaranthus tricolor L. (syn. A. gangeticus L.), Amaranthaceae, originária do Leste da Ásia (PALADA \& CROSSMAN, 1999), é planta ornamental, comestível e medicinal (PLANTS FOR A FUTURE SPECIES DATABASE BIBLIOGRAPHY, 2003). Os tons predominantemente vermelhos ou amarelos de sua folhagem inspiraram um de seus nomes populares: "fogo tropical". LORENZI \& SOUZA (2001) descreveram-no como planta herbácea, anual, ereta, que atinge de 0,80 a $1,20 \mathrm{~m}$ de altura, produzindo flores pequenas, reunidas em espigas terminais ou axilares, dando origem a sementes diminutas.

Durante alguns anos, a espécie tem sido cultivada no Viveiro Experimental de Plantas Ornamentais e Florestais da Faculdade de Ciências Agrárias e Veterinárias, Câmpus de Jaboticabal da UNESP, por meio de sementes, que são sempre coletadas para o próximo cultivo. Considerando-se que as informações sobre produção de sementes de $A$. tricolor no Brasil são escassas, o objetivo deste estudo foi descrever um ciclo de cultivo desta espécie e de avaliar sua produção de sementes em Jaboticabal.

\footnotetext{
${ }^{1}$ Extraído da Dissertação de Mestrado da primeira autora.

${ }^{2}$ Departamento de Produção Vegetal, Faculdade de Ciências Agrárias e Veterinárias, Unesp, Câmpus de Jaboticabal. Via de Acesso Prof. Paulo Donato Castellane, s/n, 14884-900, Jaboticabal (SP).

${ }^{3}$ Bolsista do CNPq. Autora para correspondência.
} 


\section{MATERIAL E MÉTODOS}

O experimento foi realizado no Viveiro Experimental de Plantas Ornamentais e Florestais da Faculdade de Ciências Agrárias e Veterinárias da Universidade Estadual Paulista (FCAV/UNESP), de agosto de 1999 a julho de 2000. O viveiro localizase no município de Jaboticabal, em altitude de 560 m, a $21^{\circ} 15^{\prime} 22^{\prime \prime}$ de latitude sul e $48^{\circ} 15^{\prime} 58^{\prime \prime}$ de longitude oeste. O clima da região, na classificação de Köppen, é Cwa, isto é, subtropical com ocorrência de chuvas no verão e inverno seco.

Coletaram-se as sementes de Amaranthus tricolor no próprio viveiro, em plantas pertencentes ao cultivar ilustrado na Figura 1, referido por GRAF (1979) como "Tampala". Para LORENZI \& SOUZA (2001), "Tampala" é o nome popular da planta, e o cultivar aqui estudado, de folhas bronzeadas, vermelhas-brilhantes e roxas, chama-se "Illumination".

A semeadura foi feita em tubetes pequenos (capacidade de $30 \mathrm{~cm}^{3}$ ) preenchidos com substrato comercial Plantmax ${ }^{\circledR}$, utilizandos-se duas bandejas com um total de 192 tubetes. Essas bandejas permaneceram em viveiro coberto com tela "sombrite" $50 \%$, de 16/8/1999 (semeadura) a 18/1/2000 (transplante). Nessa fase em viveiro, irrigaram-se as plântulas por sistema automático de aspersão e as quais receberam suplementação de nutrientes quinzenalmente, a partir de meados de outubro de 1999, com fertilizante líquido Ouro Verde ${ }^{\circledR}(6 \%$ de $\mathrm{N}$ total, $6 \%$ de $\mathrm{P}_{2} \mathrm{O}_{5}, 8 \%$ de $\mathrm{K}_{2} \mathrm{O}, 0,5 \%$ de $\mathrm{MgO}, 0,5 \%$ de $\mathrm{S}, 0,03 \%$ de $\mathrm{B}, 0,05 \%$ de $\mathrm{Zn}, 0,1 \%$ de $\mathrm{Fe}, 0,03 \%$ de $\mathrm{Mn}$ ), na proporção de $5 \mathrm{~mL}$ do produto em $2 \mathrm{~L}$ de água. Efetuaram-se avaliações semanais de altura e número de folhas das plântulas.

Em 18/1/2000, as mudas foram transplantadas para canteiro a céu aberto, com área de $10 \mathrm{~m}^{2}$, preparado com substrato contendo três partes de terra e uma de esterco curtido de bovino. A análise química dessa mistura de terra e esterco, realizada pelo Laboratório de Solo e Planta do Departamento de Solos e Adubos da FCAV/UNESP, revelou os seguintes va-

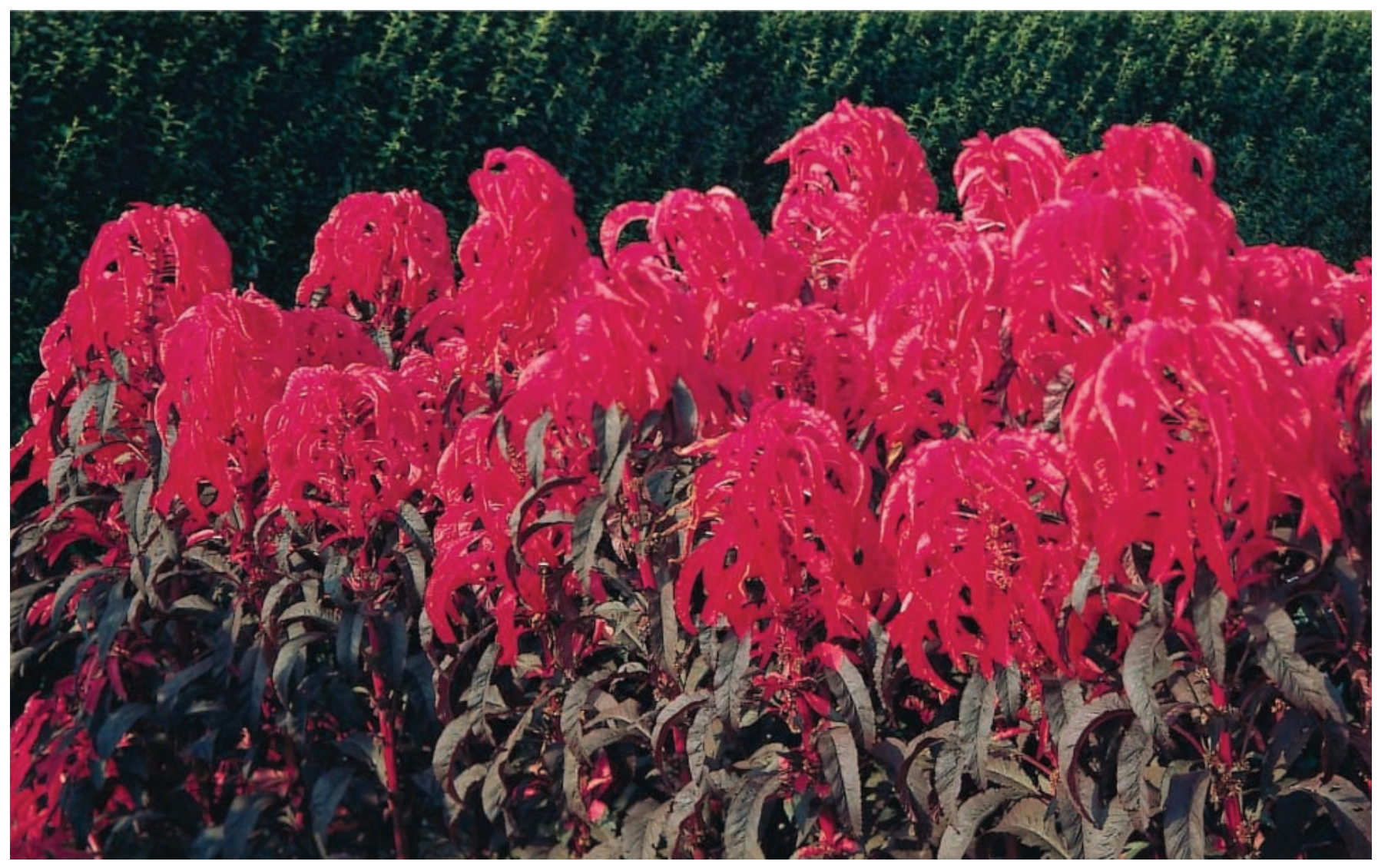

Figura 1. Amaranthus tricolor L. (tampala). Fotografia de propriedade da empresa Sakata Seed Suramerica Ltda. Reprodução autorizada por intermédio do Sr. Jorge Takizawa 
lores: $\mathrm{pH}$ em $\mathrm{CaCl}_{3}=7,3$; matéria orgânica (M.O.) $=$ $31 \mathrm{~g} / \mathrm{dm}^{3} ;$ P resina $=422 \mathrm{mg} / \mathrm{dm}^{3} ; \mathrm{K}=16,5 \mathrm{mmol}_{\mathrm{c}} /$ $\mathrm{dm}^{3} ; \mathrm{Ca}=79 \mathrm{mmol}_{\mathrm{c}} / \mathrm{dm}^{3} ; \mathrm{Mg}=30 \mathrm{mmol} / \mathrm{dm}^{3} ; \mathrm{H}+\mathrm{Al}$ $=10 \mathrm{mmol} / \mathrm{cm}^{3} ; \mathrm{SB}=125,5 \mathrm{mmol} / \mathrm{dm}^{3} ; \mathrm{T}=135,5$ $\mathrm{mmol}_{\mathrm{c}} / \mathrm{dm}^{3} ; \mathrm{V} \%=93$. Antes do transplante, o canteiro recebeu adubo NPK de fórmula 4-14-8, na quantidade de $50 \mathrm{~g} / \mathrm{m}^{2}$.

As mudas foram transplantadas obedecendo ao espaçamento de $25 \times 25 \mathrm{~cm}$, em posições intercaladas nas linhas, de modo a se obterem aproximadamente 100 plantas. Destas, 20 foram marcadas ao acaso e avaliadas semanalmente, até a coleta das sementes, quanto à altura e ao número de folhas. Considerou-se como altura da planta a distância entre a base do caule (na superfície do solo) e o ápice da parte aérea. A irrigação foi feita por aspersão, e as plantas invasoras, arrancadas manualmente.

No final do ciclo, as plantas marcadas foram coletadas inteiras. As sementes e os restos florais aderidos foram retirados e separados, assim como as folhas restantes e o caule. Essas partes foram secadas em estufa de circulação forçada de ar a $70^{\circ} \mathrm{C}$, até o peso constante, para determinação da massa seca.

As sementes utilizadas para se obterem as plantas do experimento foram avaliadas quanto à porcentagem de germinação e ao índice de velocidade de germinação (IVG), antes da semeadura (lote denominado "sementes originais recém-colhidas") e, após um ano de armazenamento em ambiente de laboratório, seco e arejado, com temperatura do ar variando de $22^{\circ}$ a $25^{\circ} \mathrm{C}$, acondicionadas em sacos de papel pardo permeável (lote denominado "sementes originais armazenadas"); as sementes produzidas (lote denominado "sementes produzidas") foram submetidas aos mesmos testes.

Efetuaram-se os testes de germinação em germinador BOD, em caixas "gerbox", com quatro repetições de 50 sementes. Estas foram colocadas sobre papel umedecido com água destilada, em temperaturas alternadas de $20-30^{\circ} \mathrm{C}$, de acordo com as recomendações das Regras para Análise de Sementes (BRASIL, 1992), permanecendo $8 \mathrm{~h}$ com luz branca e $16 \mathrm{~h}$ no escuro em cada período de $24 \mathrm{~h}$. A contagem de germinação foi feita diariamente, durante 25 dias, sendo consideradas germinadas as sementes que apresentavam protrusão de radícula igual ou superior a $3 \mathrm{~mm}$. Utilizaram-se tais resultados para o cálculo de porcentagem de germinação e do IVG segundo a fórmula de MAGUIRE (1962). Os dados foram submetidos a análise estatística para delineamento inteiramente casualizado. Os valores de porcentagem foram transformados em arco seno $(\mathrm{x})^{0,5}$.

Foram determinados os teores de água dos lotes de sementes originais armazenadas e sementes produzidas pelo método de estufa a $105^{\circ} \mathrm{C}$ por $24 \mathrm{~h}$, de acordo com as especificações das Regras para Análise de Sementes (BRASIL, 1992). A massa seca de 100 sementes foi determinada para os lotes de sementes originais e de sementes produzidas.

\section{RESULTADOS E DISCUSSÃO}

Durante o período de cultivo, a temperatura máxima registrada no local foi de $37,5^{\circ} \mathrm{C}$ (setembro de 1999) e a mínima, de $2,4^{\circ} \mathrm{C}$ (julho de 2000). A precipitação pluvial total foi máxima em janeiro de $2000(276,1 \mathrm{~mm})$ e mínima em junho de $2000(0,6$ $\mathrm{mm})$.

A porcentagem de emergência de plântulas nos tubetes foi aproximadamente igual à porcentagem de germinação das sementes em laboratório. O desenvolvimento das plantas nos tubetes, em viveiro, foi lento. Após o transplante para o canteiro definitivo, em janeiro de 2000, o crescimento foi mais rápido (Tabela 1).

Tabela 1. Variáveis avaliadas em 20 plantas de Amaranthus tricolor L. cultivadas em Jaboticabal (SP)

\begin{tabular}{|c|c|c|c|c|c|c|c|c|c|c|c|c|}
\hline \multirow{2}{*}{ Variáveis } & \multicolumn{5}{|c|}{1999} & \multicolumn{7}{|c|}{2000} \\
\hline & Ag. & Set. & Out. & Nov. & Dez. & Jan. & Fev. & Mço. & Abr. & Maio & Jun. & $\overline{\text { Jul. }}$ \\
\hline Altura média $(\mathrm{cm})$ & 0,8 & 1,7 & 2,1 & 2,1 & 2,2 & 2,5 & 6,2 & 15,6 & 20,9 & 25,2 & 30,3 & 28,0 \\
\hline Número de folhas por planta & 2,0 & 4,8 & 4,6 & 6,9 & 9,4 & 10,2 & 13,1 & 21,4 & 26,7 & 27,5 & 27,9 & 17,0 \\
\hline Massa seca de folhas por planta (g) & - & - & - & - & - & - & - & - & - & 0,74 & 0,68 & 0,24 \\
\hline Massa seca de caules por planta (g) & & - & - & - & - & - & - & - & - & 3,24 & 2,11 & 1,64 \\
\hline Massa seca de inflorescências por planta (g) & - & - & - & - & - & - & - & - & 0,54 & 0,63 & 1,32 & 1,91 \\
\hline Plantas mortas $(\%)$ & 0 & 0 & 0 & 0 & 0 & 0 & 10 & 30 & 30 & 55 & 85 & 100 \\
\hline
\end{tabular}


Durante a fase em canteiro, as plantas foram cultivadas nas condições recomendadas por LORENZI \& SOUZA (2001), vale dizer, a pleno sol, em solo úmido, com adição de fertilizantes minerais e de adubo orgânico. Mesmo assim, houve grande mortalidade a partir de fevereiro (Tabela 1), atribuída ao insucesso do transplante. Muitas plantas sobreviventes cresceram com forma defeituosa, prostradas e recurvadas.

$\mathrm{Na}$ literatura, há recomendações para fazer-se a semeadura em viveiro com posterior transplante para canteiros (WINTER, 2003) ou semear diretamente no local definitivo (STEPHENS, 2003). No Viveiro Experimental, local deste experimento, em cultivos anteriores, as plantas de A. tricolor desenvolveram-se bem quando semeadas diretamente no canteiro definitivo.

Neste trabalho, optou-se pela semeadura em tubetes com posterior transplante porque, no período inicial, era conveniente que as plântulas estivessem em ambiente protegido, considerando-se a possibilidade de ocorrência de baixas temperaturas. Os resultados, entretanto, indicaram que o transplante, nas condições de Jaboticabal, não é recomendável.

As médias do número de folhas por planta e de altura foram crescentes desde o início do desenvolvimento até junho de 2000, decrescendo em julho, no final do ciclo, quando as plantas estavam senescentes (Tabela 1).

A massa seca de folhas e caules (Tabela 1) começou a ser avaliada em maio de 2000, com base nas plantas secas coletadas.

A floração teve início em abril de 2000, ocorrendo em todas as plantas sobreviventes $(70 \%$ do total). As médias de massa seca de inflorescências das plantas amostradas foram crescentes até o final do experimento (Tabela 1), mostrando aumento de peso em decorrência da formação e do aumento da quantidade de sementes. Estas foram coletadas do final de abril até julho, considerando-se maduras aquelas de inflorescências completamente secas ocorrentes em plantas no final do ciclo. Foram necessários, portanto, de 8 a 11 meses, a partir da semeadura, para colher sementes maduras. Considerando somente as plantas que chegaram a produzir inflorescências $(70 \%)$, a produção de sementes por planta foi de $2,71 \mathrm{~g}$.

O teor de água das sementes produzidas foi de $17,3 \%$, inferior ao do lote de sementes originais, que, no final do período de armazenamento, apresentavam $26,8 \%$ de água. A colheita de sementes no in- verno, época do ano mais seca em Jaboticabal, propiciou esse baixo valor. De acordo com CARVALHO \& NAKAGAWA (2000), menor teor de água na semente favorece a conservação de sua viabilidade durante o armazenamento. De modo geral, para produção de sementes de boa qualidade fisiológica, é importante que a fase final de maturação e a colheita coincidam com a época mais seca, por isso, o mês de agosto, em Jaboticabal, foi adequado para a semeadura. LORENZI \& SOUZA (2001) recomendaram que a semeadura de A. tricolor seja feita na primavera; nas condições locais, entretanto, se a semeadura fosse feita a partir do final de setembro, a maturação das sementes produzidas poderia ocorrer em períodos chuvosos.

A massa seca de 100 sementes foi de $0,0103 \mathrm{~g}$, valor esse inferior ao da massa seca de 100 sementes do lote utilizado para obter as plantas matrizes $(0,0149 \mathrm{~g})$. Em uma mesma espécie, sementes maiores ou mais pesadas podem estar relacionadas com melhor qualidade fisiológica (DEMATTÊ et al., 1987).

As sementes produzidas apresentaram porcentagem e velocidade de germinação menores do que as utilizadas para obtenção das plantas matrizes (Tabela 2). Isso pode ser atribuído ao mau desenvolvimento das plantas matrizes depois de transplantadas, com possível prejuízo da qualidade fisiológica de suas sementes.

Quando comparadas com os resultados dos melhores tratamentos em experimentos realizados por outros autores, as porcentagens de germinação das sementes produzidas no presente estudo foram baixas (54,5\%). OLADIRAN \& MUMFORD (1985 e 1990) verificaram quase $100 \%$ de germinação com sementes de Amaranthus gangeticus (syn. A. tricolor). SANTOS et al. (2001), trabalhando com sementes comerciais de A. tricolor cv. Splendens Perfecta, obtiveram $87 \%$ de germinação. As condições em que foram produzidas as sementes utilizadas por esses autores não foram mencionadas em seus trabalhos.

Em experimento de OLADIRAN \& MUMFORD (1990), o Índice de Velocidade de Germinação de sementes de $A$. gangeticus diminuiu à medida que aumentou o período de armazenamento. No presente trabalho, após um ano de armazenamento em condições não controladas de ambiente de laboratório, descritas em MATERIAL E MÉTODOS, a germinação das sementes de $A$. tricolor não sofreu prejuízo significativo (Tabela 2), o que leva à suposição de que as sementes dessa espécie poderiam ser armazenadas durante o período de 12 meses sem grandes problemas. 
Tabela 2. Porcentagem de germinação e índice de velocidade de germinação (IVG) de sementes de Amaranthus tricolor L.

\begin{tabular}{|c|c|c|c|}
\hline \multirow{2}{*}{$\frac{\text { Lotes }}{\text { Sementes originais recém-colhidas }}$} & \multicolumn{2}{|c|}{ Germinação ${ }^{(1)}$} & \multirow{2}{*}{$\frac{\mathrm{IVG}^{(1)}}{5,77 \mathrm{a}}$} \\
\hline & $90,00^{(2)}$ & $77,09 \mathrm{a}^{(3)}$ & \\
\hline Sementes originais armazenadas (um ano) & 79,50 & $63,28 \mathrm{ab}$ & $3,93 \mathrm{ab}$ \\
\hline Sementes produzidas & 54,50 & $47,59 \mathrm{~b}$ & $2,45 \mathrm{~b}$ \\
\hline $\mathrm{F}$ & & $9,28 * *$ & $8,90 * *$ \\
\hline DMS & & 18,70 & 2,22 \\
\hline CV $(\%)$ & & 15,47 & 27,49 \\
\hline
\end{tabular}

${ }^{1}$ Médias seguidas de mesma letra não diferem entre si pelo teste de Tukey (5\%). ${ }^{2}$ Dados originais em porcentagem. ${ }^{3}$ Dados transformados em arco seno $(\mathrm{x})^{0,5} \cdot * *=$ significativo a $1 \%$ de probabilidade pelo teste de Tukey. DMS $=$ Diferença mínima significativa. CV $=$ Coeficiente de variação.

\section{CONCLUSÕES}

Confirmou-se a possibilidade de cultivo e produção de sementes de Amaranthus tricolor em Jaboticabal. São necessários futuros estudos com o objetivo de melhorar-lhes a qualidade fisiológica, recomendando-se, para continuação da pesquisa, que a semeadura seja feita no canteiro definitivo, sem transplante.

\section{AGRADECIMENTOS}

As autoras agradecem à Prof. Dra. Regina Maria Monteiro de Castilho, ao Sr. Jorge Takizawa e à Sakata Seed Suramerica Ltda., por terem possibilitado a utilização da fotografia de Amaranthus tricolor L. Agradecem também à Professora Regina e à Prof. Dra. Kathia Fernandes Lopes Pivetta, as sugestões.

\section{REFERÊNCIAS BIBLIOGRÁFICAS}

BRASIL. Ministério da Agricultura e Reforma Agrária. Regras para análise de sementes. Brasília: SNDA/DNDV/ CLV, 1992. 365p.

CARVALHO, N.M. \& NAKAGAWA, J. Sementes: ciência, tecnologia e produção. 4.ed. Jaboticabal: FUNEP, 2000. $588 \mathrm{p}$.

DEMATTÊ, M.E.S.P.; HAAG, H.P.; PERECIN, D. \& VASQUES, L.H. Nitrogênio, fósforo, potássio, adubo orgânico e calcário dolomítico na produção de sementes de grama-batatais (Paspalum notatum Flügge) em latossolo vermelho escuro. Anais da Escola Superior de Agricultura Luiz de Queiroz, Piracicaba, v.44, p.571616, 1987.

GRAF, A.B. Tropica: color cyclopedia of exotic plants and trees from the tropics and subtropics. New Jersey: Roehrs, 1979. p.52.
LORENZI, H. \& SOUZA, H.M. de. Plantas ornamentais no Brasil: arbustivas, herbáceas e trepadeiras. 3.ed. Nova Odessa: Plantarum, 2001. p.132.

MAGUIRE, J.D. Speed of germination - aid selection and evaluation for seedling emergence and vigor. Crop Science, Madison, v.2, p.176-177, 1962.

OLADIRAN, J.A. \& MUMFORD, P.M. The longevity of large and small seeds of Amaranthus gangeticus and $A$. hybridus. Seed Science and Technology, Zurich, v.18, n.3, p.499-506, 1990.

OLADIRAN, J.A. \& MUMFORD, P.M. The stimulation of seed germination by temperature and light in agronomic Amaranthus species. Biochemie und Physiologie der Pflanzen, Jena, v.180, n.1, p.45-54, 1985.

PALADA, M.C. \& CROSSMAN, S.M.A. Evaluation of tropical leaf vegetables in the Virgin Islands. In: JANICK, J. (Ed.). Perspectives on new crops and new uses. Alexandria: ASHS Press, 1999. p.388-393.

PLANTS FOR A FUTURE SPECIES DATABASE BIBLIOGRAPHY. Amaranthus tricolor. Disponível em $<$ http://gardenbed.com/source/5/430_cul.asp $>$. Acesso em: $1 \% / 8 / 2003$.

SANTOS, F.P. dos \& CASTILHO, R.M.M. de. Estudo da germinação de Amaranthus tricolor cv. Splendens Perfecta. In: CONGRESSO DE INICIAÇÃ O CIENTÍFICA DA UNESP, 13., Bauru, 2001. Resumos: CiênciasBiológicas... Bauru, Universidade Estadual Paulista, 2001. p. 250 .

STEPHENS, J.M. Amaranth - Amaranthus spp. University of Florida, Cooperative Extension Service, Institute of Food and Agricultural Sciences - EDIS. Disponível em: $<$ http://edis.ifas.ufl.edu/BODY_MV006>. Acesso em: 28/ $11 / 2003$.

WINTER, N. Summer poinsettia yields flashy color. Mississipi State University, Office of Agricultural Communications. Disponível em: $<\mathrm{http}: / / \mathrm{msucares} . c o m /$ news/print/sgnews/sg01/sg010730.html > Acesso em: 28/ 11/2003. 